Article

\title{
Effects of Forces, Particle Sizes, and Moisture Contents on Mechanical Behaviour of Densified Briquettes from Ground Sunflower Stalks and Hazelnut Husks
}

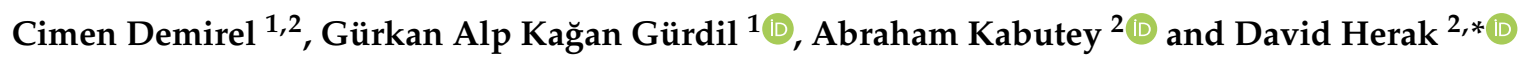 \\ 1 Department of Agricultural Machinery, Faculty of Agriculture, Ondokuz Mayis University, \\ 55139 Samsun, Turkey; cimendemirel@gmail.com (C.D.); ggurdil@omu.edu.tr (G.A.K.G.) \\ 2 Department of Mechanical Engineering, Faculty of Engineering, Czech University of Life Sciences Prague, \\ Kamycka 129, 16521 Prague, Czech Republic; kabutey@tf.czu.cz \\ * Correspondence: herak@tf.czu.cz; Tel.: +420-224-383-181
}

Received: 21 April 2020; Accepted: 14 May 2020; Published: 17 May 2020

\begin{abstract}
Using the uniaxial compression process, the mechanical behaviour of densified briquettes from ground sunflower stalks and hazelnut husks was studied under different forces $(100,200,300$, and $400 \mathrm{kN}$ ), particle sizes $(0,3,6$, and $10 \mathrm{~mm}$ ), and moisture contents (sunflower; $11.23 \%, 14.44 \%$, and $16.89 \%$ w.b.) and (hazelnut; $12.64 \%, 14.83 \%$, and $17.34 \%$ w.b.) at a constant speed of $5 \mathrm{~mm} \mathrm{~min}^{-1}$. For each test, the biomass material was compacted at a constant volume of $28.27 \times 10^{-5} \mathrm{~m}^{3}$ using a $60 \mathrm{~mm}$-diameter vessel. Determined parameters included densification energy (J), hardness $\left(\mathrm{kN} \cdot \mathrm{mm}^{-1}\right)$, analytical densification energy $(\mathrm{J})$, briquette volume $\left(\mathrm{m}^{3}\right)$, bulk density of materials $\left(\mathrm{kg} \cdot \mathrm{m}^{-3}\right)$, briquette bulk density $\left(\mathrm{kg} \cdot \mathrm{m}^{-3}\right)$, and briquette volume energy $\left(\mathrm{J} \cdot \mathrm{m}^{-3}\right)$. The ANOVA multivariate tests of significance results showed that for ground sunflower stalk briquettes, the force and particle size interactions had no significant effect $(p>0.05)$ on the above-mentioned parameters compared to the categorical factors, which had a significant effect $(p<0.05)$ similar to the effects of forces, moisture contents, and their interactions. For ground hazelnut husk briquettes, all the factors and their interactions had a significant effect on the determined parameters. These biomass materials could be attractive for the briquette market.
\end{abstract}

Keywords: biomass densification; mechanical compaction; processing factors; briquette durability; multivariate tests of significance

\section{Introduction}

Agricultural residues in the form of straws, grasses, stalks, and husks (among others) are excellent sources for biofuel production [1-3]. One of the major limitations of using biomass as a feedstock is its low bulk density, which ranges from 80 to $100 \mathrm{~kg} / \mathrm{m}^{3}$ for agricultural straws and grasses and from 150 to $200 \mathrm{~kg} / \mathrm{m}^{3}$ for woody resources such as wood chips and sawdust [4] Inefficient transportation and large volume requirements for storage are some of the challenges associated with biomass energy usage [5]. Biomass densification for both bioenergy and animal feed utilization has been the approach to mitigate the cost of transportation, handling, and storage [6,7]. Additionally, densified biomass improves fuel feeding in co-firing operations and provides an increased regulation of combustion, thus reducing particulate emissions [8-10]. Densification is widely used in biomass industries, animal feed making, and pharmaceutical industries, and it is classified into pelletization, briquetting, and extrusion $[10,11]$. Biomass densification is defined as the compression or compaction of biomass to remove inter-and intra-particle voids [5,12]. Generally, the densification of materials requires two 
stages to take place: particle rearrangement and deformation [1,13-16]. According to [17], as cited in [1], in the first stage, particles rearrange to bring themselves closer together and to reduce voids; little stress is needed to overcome interparticle and particle-to-wall friction. The particles retain their properties, and elastic deformation mainly occurs during this phase [18]. In the second stage, with increasing applied pressure, most of the air is removed from the particulate mass and the elastic-plastic deformation of particles occurs [13-16,18,19].

Recently, studies have been conducted on biomass briquette densification to improve the performance of briquetting technology and to determine the optimum processing factors for producing quality briquettes for energy purposes [2,11,20-26]. The energy requirement for the densification of biomass primarily depends upon the pressure applied and the moisture content of the material to be compressed, as well as the physical properties of the material, including particle size and initial bulk density [8]. The sustainability of biomass densification depends on the energy consumption, emissions, and cost integrated with densification itself and the application of the densified biomass in the combustion or gasification process $[6,27]$. The machinery for biomass densification is experiencing greatly increasing interest as a result of the concern for its easier mechanical handling of biomass residues, lower storage, and transport space. However, the performance of the briquetting technology is influenced by several operating factors such as pressure, biomass type, particle size, quality, moisture content, feed rate, the forward speed of the machine, field conditions, feeding mechanisms, and power [2]. To optimize the operating factors and the design of new technology for producing biomass briquettes, it is imperative to study and understand the mechanical and rheological behaviours of biomass materials under uniaxial compression [1,28-33].

This information regarding briquette densification from ground sunflower stalks and hazelnut husks with the processing factors is inadequate in the literature. There is also an increasing need to source alternative fuels, especially for cooking to reduce deforestation in the rural areas of developed, developing, and underdeveloped countries. Therefore, these biomass materials could be economically attractive for fuel applications. The objectives of the study were to (i) experimentally and theoretically describe the force and deformation curves of densified briquettes from ground sunflower stalks and hazelnut husks and (ii) to calculate the densification energy (J), hardness $(\mathrm{kN} / \mathrm{mm})$, analytical energy (J), briquette volume $\left(\mathrm{m}^{3}\right)$, bulk density of materials $\left(\mathrm{kg} / \mathrm{m}^{3}\right)$, briquette bulk density $\left(\mathrm{kg} / \mathrm{m}^{3}\right)$, and briquette volume energy $\left(\mathrm{J} / \mathrm{m}^{3}\right)$.

\section{Materials and Methods}

\subsection{Samples, Milling and Particle Size Distributions}

Sunflower stalks and hazelnut husks (Figure 1A,B) were brought from Samsun, Turkey to the Faculty of Engineering, Department of Mechanical Engineering, Czech University of Life Sciences Prague, Prague, Czech Republic. The biomass materials were ground using a hammer mill with a $5.5 \mathrm{~kW}$ motor (9FQ-40C, Pest Control Corporation, s.r.o., Vlčnov, Czech Republic) (Figure 1C). The particle size distributions of the ground biomass materials were determined according to the American Society of Agricultural Engineering (ASAE) S319.3 standard [34]. Based on the standard procedure, $100 \mathrm{~g}$ of the ground materials were successively placed on top of a sieve shaker (AS 200, Retsch, Haan, Germany) (Figure 1D) of four sieve opening sizes in the order of $0-3,3-6,6-10$, and/or $>6 \mathrm{~mm}$. The sieve shaker was vibrated for $10 \mathrm{~min}$ at an amplitude of $3.0 \mathrm{~mm} / \mathrm{g}$. Ground material of a particle size of $0-10$ and/or $>6 \mathrm{~mm}$ served as the control. 
(B)

(A)
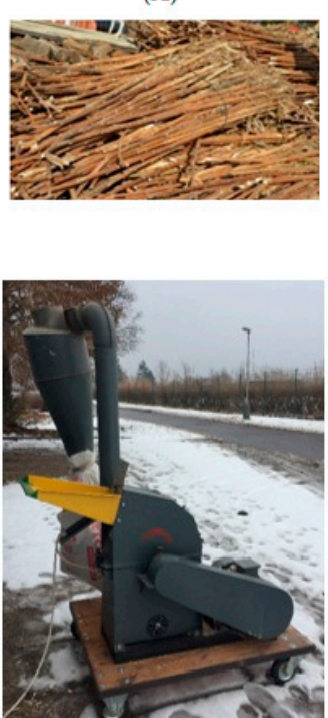

(C)
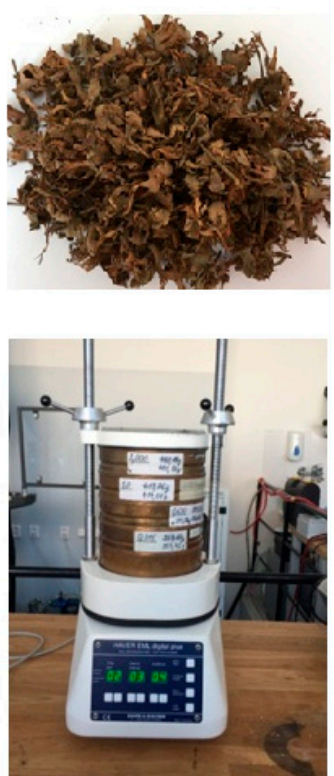

(D)

Figure 1. (A) Sunflower stalks and (B) hazelnut husks. (C) A $5.5 \mathrm{~kW}$ motor hammer mill (9FQ-40C, Pest Control Corporation, s.r.o., Vlčnov, Czech Republic) used to grind the biomass materials. (D) A sieve shaker (AS 200, Retsch, Haan, Germany) of four sieve opening sizes.

\subsection{Determination of Moisture Content and Moisture Conditioning}

The initial moisture contents of the ground sunflower stalks and hazelnut husks of $11.23 \%$ w.b. and $12.64 \%$, respectively, was determined using the standard oven method [35-37]. The particle size of 0-10 $\mathrm{mm}$ of the ground sunflower stalks (Figure 2A) was conditioned to moisture contents of $14.44 \%$ and $16.89 \%$ (w.b.). The particle size of $0-6 \mathrm{~mm}$ of the ground hazelnut husks (Figure 2B) was also conditioned to moisture contents of $14.83 \%$ and $17.34 \%$ (w.b.). Moisture conditioning equipment (MEMMERT GmbH + Co. KG, Schwabach, Germany) was used. The equipment was equipped with a tube connected to a $2 \mathrm{~L}$ gallon on top of it that was filled with distilled water whenever necessary. The samples were loaded into the oven with the parameter settings of a $50{ }^{\circ} \mathrm{C}$ temperature with a $\pm 2{ }^{\circ} \mathrm{C}$ minimum and maximum to regulate the actual temperature for each relative humidity value between $60 \%$ and $90 \%$ for $24 \mathrm{~h}$. Afterwards, the samples were put into a conventional oven for $24 \mathrm{~h}$ to determine their moisture values.

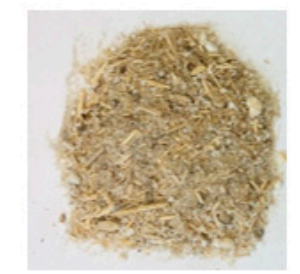

$0(0-10 \mathrm{~mm})$

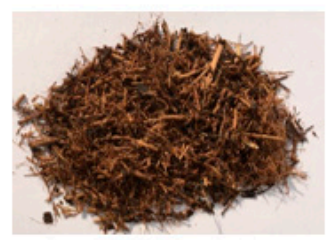

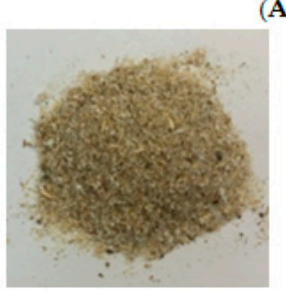

$3(0-3 \mathrm{~mm})$

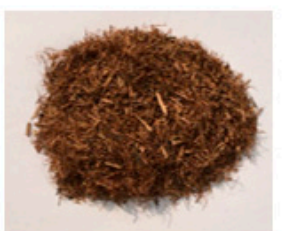

A)

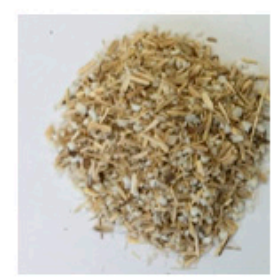

$6(3-6 \mathrm{~mm})$

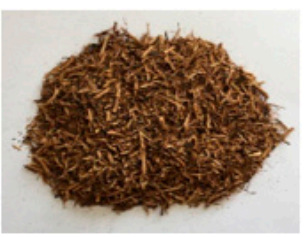

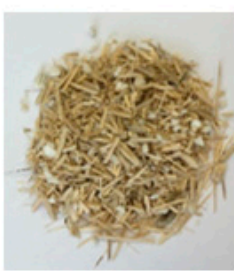

$10(6-10 \mathrm{~mm})$

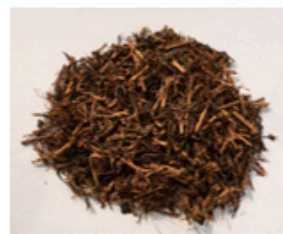

(B)

Figure 2. (A) Ground sunflower stalks. (B) Ground hazelnut husks of different size distributions. 


\subsection{Biomass Briquettes Densification}

Each of the particle size and moisture content values of the ground biomass materials was densified using a universal compression-testing machine (Tempos, model ZDM 50, Czech Republic) (Figure 3) along with a pressing vessel of diameter $60 \mathrm{~mm}$ with a plunger under varying forces $(\mathrm{F})$ between 100 and $400 \mathrm{kN}$ at a speed of $5 \mathrm{~mm} / \mathrm{min}$, where the dependencies between the forces and deformation curves were obtained. The initial pressing height $(\mathrm{H})$ of the material was measured at $100 \mathrm{~mm}$ using the above mentioned vessel diameter, which remained constant for all tests. Based on this measurement, the volume of the biomass material was calculated to be $28.27 \times 10^{-5} \mathrm{~m}^{3}$. Two separate experiments were performed for the two types of biomass materials. The first experiment considered the input factors of forces and particle sizes at a constant moisture content of the biomass material $(4 \times 4=$ $16 \times 2=32$ ) for two replications. The second experiment considered the input factors of forces and moisture contents at a constant particle size $(4 \times 3=12 \times 2=24)$ for two replications. This makes a total of 56 experiments multiplied by 2 types of materials, thus making 112 experiments. However, the actual number of experiments was 96 as a result of the constant factors. Average values were used in all calculations.

(A)
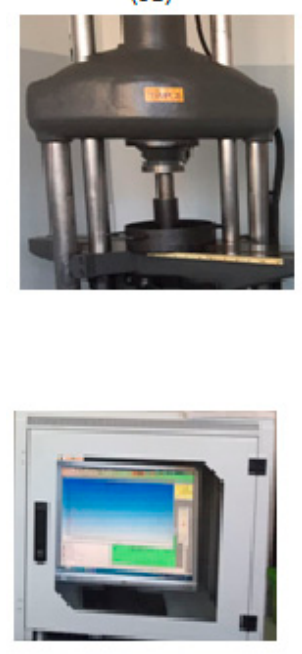

(B)
(C)
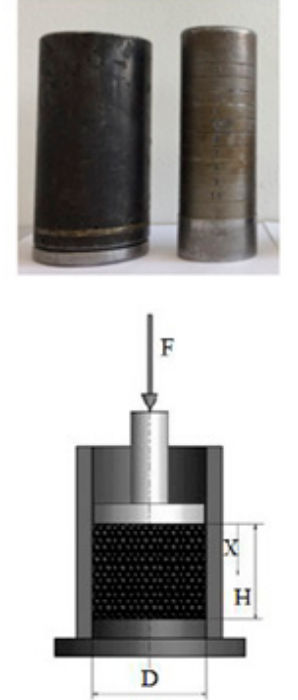

(D)
(E)
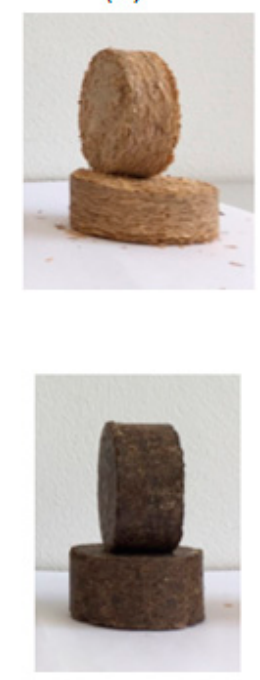

(F)

Figure 3. (A) Compression test process. (B) A computer monitor for data display. (C) Pressing vessel with a plunger. (D) Schematic of the pressing vessel with a plunger showing the force $(\mathrm{F}(\mathrm{kN}))$, deformation $(X(\mathrm{~mm}))$, and the initial height of the sample $(\mathrm{H}(\mathrm{mm}))$ [28]. (E) Densified sunflower briquettes. (F) Densified hazelnut briquettes.

\subsection{Densification Tests Calculated Parameters}

The parameters calculated from the densification tests included densification energy (J), hardness $\left(\mathrm{kN} \cdot \mathrm{mm}^{-1}\right)$, analytical densification energy $(\mathrm{J})$, briquette volume $\left(\mathrm{m}^{3}\right)$, bulk density of materials $\left(\mathrm{kg} \cdot \mathrm{m}^{-3}\right)$, briquette bulk density $\left(\mathrm{kg} \cdot \mathrm{m}^{-3}\right)$, and briquette volume energy $\left(\mathrm{J} \cdot \mathrm{m}^{-3}\right)$ with respect to compression forces, particle sizes, and moisture contents using the mathematical equations described in our previous publication on jatropha seedcake briquettes [28]. Other parameters that were directly determined from the densification tests were deformation and briquette thickness. The thickness of the briquettes was measured using a Digital Vernier Caliper. The calculated bulk density at various particle sizes and moisture contents of ground sunflower stalks ranged from 170.99 to $192.54 \mathrm{~kg} \cdot \mathrm{m}^{-3}$, whereas that of ground hazelnut husks ranged from 204.43 to $355.09 \mathrm{~kg} \cdot \mathrm{m}^{-3}$. 


\subsection{Statistical Analyses}

The calculated parameters were statistically analysed using Statistica 13 software [38] by employing the ANOVA, regression, and correlation methods. The theoretical dependencies between the forces and deformation curves were described using the MathCAD 14 software [39] based on the tangent curve function $[28,40-43]$, where the analytical energies of the densified briquettes were determined.

\section{Results}

\subsection{Deformation, Thickness, Densification Energy and Hardness of Ground Sunflower Stalks Briquettes}

The determined amounts of the deformation, thickness, densification energy, and hardness of densified ground sunflower stalk briquettes in relation to the combined effects of forces, particle sizes, and moisture contents are given in Tables 1 and 2. The deformation values ranged from 87.63 to $106.73 \mathrm{~mm}$, and both increased and decreased trends were observed with increased forces, particle sizes, and moisture contents, thus indicating that the deformation values tended to not be affected by the observed factors. Briquettes thickness ranged from 18.45 to $27.34 \mathrm{~mm}$ for forces, particle sizes, and moisture contents. Briquette thickness decreased with increased particle sizes but increased with moisture contents for all forces. However, for the particle size of $10 \mathrm{~mm}$ at forces 200 and $300 \mathrm{kN}$, the values increased, which could have been due to the large intercellular air space of the biomass cell walls, which is important for bonding, For all forces, densification energy values increased with increased particle sizes but decreased with moisture contents. The values ranged from 783.88 to $2092 \mathrm{~J}$. Hardness values decreased along with increased forces and particle sizes. However, at force $300 \mathrm{kN}$, hardness values increased at particle sizes between 0 and $6 \mathrm{~mm}$ and then decreased at $10 \mathrm{~mm}$. The values ranged from 1.01 to $4.27 \mathrm{kN} \cdot \mathrm{mm}^{-1}$.

Table 1. Deformation, thickness, densification energy, and hardness of ground sunflower stalks with forces and particle sizes.

\begin{tabular}{|c|c|c|c|c|c|}
\hline Force $F(\mathbf{k N})$ & $\begin{array}{c}\text { Particle Size } \\
\text { PS (mm) }\end{array}$ & $\begin{array}{l}\text { Deformation } X \\
\quad(\mathrm{~mm})\end{array}$ & $\begin{array}{c}\text { Thickness TK } \\
\text { (mm) }\end{array}$ & $\begin{array}{l}\text { Densification } \\
\text { Energy EN (J) }\end{array}$ & $\begin{array}{c}\text { Hardness } H R \\
\left(\mathrm{kN} \cdot \mathrm{mm}^{-1}\right)\end{array}$ \\
\hline \multirow{4}{*}{100} & $* 0$ & $92.49 \pm 6.60$ & $25.72 \pm 0.35$ & $924.87 \pm 61.72$ & $1.08 \pm 0.08$ \\
\hline & 3 & $89.19 \pm 0.81$ & $27.27 \pm 0.06$ & $880.34 \pm 44.49$ & $1.12 \pm 0.01$ \\
\hline & 6 & $90.88 \pm 3.45$ & $26.67 \pm 3.01$ & $971.22 \pm 94.06$ & $1.10 \pm 0.04$ \\
\hline & 10 & $100.98 \pm 19.11$ & $25.67 \pm 2.19$ & $1038.46 \pm 221.20$ & $1.01 \pm 0.19$ \\
\hline \multirow{4}{*}{200} & $* 0$ & $99.31 \pm 1.35$ & $21.99 \pm 0.69$ & $1314.96 \pm 39.07$ & $2.01 \pm 0.03$ \\
\hline & 3 & $87.63 \pm 4.26$ & $21.70 \pm 1.82$ & $1316.38 \pm 96.59$ & $2.28 \pm 0.11$ \\
\hline & 6 & $94.60 \pm 2.77$ & $21.45 \pm 0.47$ & $1433.54 \pm 149.11$ & $2.11 \pm 0.06$ \\
\hline & 10 & $106.73 \pm 15.05$ & $21.57 \pm 2.94$ & $1463.52 \pm 224.57$ & $1.89 \pm 0.27$ \\
\hline \multirow{4}{*}{300} & $* 0$ & $94.81 \pm 2.02$ & $20.15 \pm 0.58$ & $1616.09 \pm 58.69$ & $3.16 \pm 0.07$ \\
\hline & 3 & $94.77 \pm 5.28$ & $19.92 \pm 0.43$ & $1679.75 \pm 71.99$ & $3.17 \pm 0.18$ \\
\hline & 6 & $94.12 \pm 4.57$ & $19.56 \pm 2.15$ & $1673.74 \pm 203.98$ & $3.19 \pm 0.16$ \\
\hline & 10 & $102.59 \pm 11.36$ & $19.72 \pm 3.22$ & $1781.96 \pm 308.30$ & $2.94 \pm 0.33$ \\
\hline \multirow{4}{*}{400} & $* 0$ & $94.45 \pm 8.10$ & $18.45 \pm 0.10$ & $1942.61 \pm 72.22$ & $4.25 \pm 0.36$ \\
\hline & 3 & $94.15 \pm 9.36$ & $19.95 \pm 0.45$ & $1969.24 \pm 52.88$ & $4.27 \pm 0.42$ \\
\hline & 6 & $95.31 \pm 2.28$ & $18.78 \pm 1.90$ & $1983.79 \pm 206.98$ & $4.20 \pm 0.10$ \\
\hline & 10 & $104.15 \pm 15.61$ & $18.68 \pm 3.34$ & $2092.96 \pm 350.82$ & $3.88 \pm 0.58$ \\
\hline
\end{tabular}

* 0 (0-10)—control, 3 (3-6), 6 (3-6) and 10 (6-10) $\mathrm{mm}$.

The multivariate results of significance and correlation of the effects of forces/particle sizes and forces/moisture contents on energy and hardness are given in Tables 3 and 4 . The effects of the forces, particle sizes, and moisture contents and their interactions on deformation, thickness, densification energy, and hardness were interpreted based on Wilk's lambda value, F-value, and $p$-value. For all determined parameters, the correlation between thickness, densification energy, hardness, and forces were higher compared to particle sizes and moisture contents. 
Table 2. Deformation, thickness, densification energy, and hardness of ground sunflower stalks with forces and moisture contents.

\begin{tabular}{|c|c|c|c|c|c|}
\hline Force $F(\mathbf{k N})$ & $\begin{array}{c}\text { Moisture Content } \\
\text { MC }(\% \text { w.b. })\end{array}$ & $\begin{array}{l}\text { Deformation } X \\
\quad(\mathrm{~mm})\end{array}$ & $\begin{array}{c}\text { Thickness } T K \\
\text { (mm) }\end{array}$ & $\begin{array}{l}\text { Densification } \\
\text { Energy } E N(\mathrm{~J})\end{array}$ & $\begin{array}{c}\text { Hardness } H R \\
\left(\mathrm{kN} \cdot \mathrm{mm}^{-1}\right)\end{array}$ \\
\hline \multirow{3}{*}{100} & 11.23 & $92.49 \pm 6.60$ & $25.72 \pm 0.35$ & $924.87 \pm 61.72$ & $1.08 \pm 0.08$ \\
\hline & 14.44 & $95.68 \pm 2.62$ & $24.97 \pm 0.28$ & $786.50 \pm 13.98$ & $1.05 \pm 0.03$ \\
\hline & 16.89 & $102.51 \pm 0.59$ & $27.34 \pm 0.08$ & $783.88 \pm 5.52$ & $1.08 \pm 0.08$ \\
\hline \multirow{3}{*}{200} & 11.23 & $99.31 \pm 1.35$ & $21.99 \pm 0.69$ & $1314.96 \pm 39.07$ & $2.01 \pm 0.03$ \\
\hline & 14.44 & $96.12 \pm 0.28$ & $21.67 \pm 0.32$ & $1104.19 \pm 19.45$ & $2.08 \pm 0.01$ \\
\hline & 16.89 & $96.26 \pm 0.88$ & $22.95 \pm 0.37$ & $1066.98 \pm 16.96$ & $2.01 \pm 0.03$ \\
\hline \multirow{3}{*}{300} & 11.23 & $94.81 \pm 2.02$ & $20.15 \pm 0.58$ & $1616.09 \pm 58.69$ & $3.17 \pm 0.07$ \\
\hline & 14.44 & $93.89 \pm 6.78$ & $19.48 \pm 0.33$ & $1378.49 \pm 0.68$ & $3.20 \pm 0.23$ \\
\hline & 16.89 & $102.56 \pm 0.57$ & $21.78 \pm 0.42$ & $1326.65 \pm 9.39$ & $3.17 \pm 0.07$ \\
\hline \multirow{3}{*}{400} & 11.23 & $94.45 \pm 8.10$ & $18.45 \pm 0.10$ & $1942.61 \pm 72.22$ & $4.25 \pm 0.36$ \\
\hline & 14.44 & $100.73 \pm 1.88$ & $19.27 \pm 0.04$ & $1607.68 \pm 15.66$ & $3.97 \pm 0.07$ \\
\hline & 16.89 & $101.52 \pm 0.20$ & $21.10 \pm 0.08$ & $1528.55 \pm 34.17$ & $4.25 \pm 0.36$ \\
\hline
\end{tabular}

Table 3. ANOVA multivariate tests of significance of the determined parameters of ground sunflower stalk briquettes.

\begin{tabular}{ccccccc}
\hline Effect & Test & Wilks Value & F-Value (-) & Effect $d f$ & Error $d f$ & $p$-Value (-) \\
\hline \multicolumn{7}{c}{ Effects of $\boldsymbol{F}$ and $\boldsymbol{P S}$} \\
\hline Intercept & Wilks lambda & $<0.05$ & 6197.566 & 7 & 10.000 & $<0.05$ \\
$F$ & Wilks lambda & $<0.05$ & 23.061 & 21 & 29.265 & $<0.05$ \\
$P S$ & Wilks lambda & $<0.05$ & 3.109 & 21 & 29.265 & $<0.05$ \\
$F \times P S$ & Wilks lambda & $>0.05$ & 0.631 & 63 & 62.429 & $>0.05$ \\
\hline \multicolumn{7}{c}{ Effects of $\boldsymbol{F}$ and $\boldsymbol{M C}$} \\
\hline Intercept & Wilks lambda & $<0.05$ & $3,542,185$ & 7 & 6.000 & $<0.05$ \\
$F$ & Wilks lambda & $<0.05$ & 79 & 21 & 17.779 & $<0.05$ \\
$M C$ & Wilks lambda & $<0.05$ & 163 & 14 & 12.000 & $<0.05$ \\
$F \times M C$ & Wilks lambda & $<0.05$ & 7 & 42 & 31.595 & $<0.05$ \\
\hline
\end{tabular}

$F$ : force (kN); PS: particle size (mm); MC: moisture content (\% w.b.); $d f$ : degree of freedom.

Table 4. Correlation results of the determined parameters against force, particle size, and moisture content of ground sunflower stalk briquettes.

\begin{tabular}{ccccc}
\hline \multirow{2}{*}{ Determined Parameters } & \multicolumn{4}{c}{ Correlation } \\
\cline { 2 - 5 } & $\boldsymbol{F}$ & $\boldsymbol{P S}$ & $\boldsymbol{F}$ & $\boldsymbol{M C}$ \\
\hline Deformation $(\mathrm{mm})$ & 0.14 & 0.40 & 0.15 & 0.52 \\
Thickness $(\mathrm{mm})$ & -0.84 & -0.04 & -0.89 & 0.29 \\
Densification Energy $(\mathrm{J})$ & 0.94 & 0.14 & 0.93 & -0.31 \\
Analytical Densification Energy $(\mathrm{J})$ & 0.74 & -0.16 & 0.66 & 0.04 \\
Volume $\left(\times 10^{-5} \mathrm{~m}^{3}\right)$ & -0.84 & -0.04 & -0.89 & 0.29 \\
Bulk Density $\left(\mathrm{kg} \cdot \mathrm{m}^{-3}\right)$ & 0.89 & -0.07 & 0.93 & -0.09 \\
Hardness $\left(\mathrm{kN} \cdot \mathrm{mm}^{-1}\right)$ & 0.98 & 0.07 & 0.99 & 0.01 \\
Volume Energy $\left(\times 10^{6} \mathrm{~J} \cdot \mathrm{m}^{-3}\right)$ & 0.98 & 0.12 & 0.92 & -0.33 \\
\hline
\end{tabular}

F: force (kN); PS: particle size (mm); MC: moisture content (\% w.b.).

The regression results of the densification energy and hardness of the densified briquettes of ground sunflower stalks with the effects of forces/particle sizes and forces/moisture contents are given in Tables 5 and 6 . The results in Tables 5 and 6 represent an example of the regression models of other dependent variables which are highlighted in the discussion section. The models for densification energy and hardness with forces/particle sizes and forces/moisture contents are indicated. The suitability of the models was assessed by the coefficient of determination $\left(R^{2}\right), F$-values, and $p$-values. 
Table 5. Regression results of energy and hardness of ground sunflower stalk briquettes with the effects of force and particle size.

\begin{tabular}{|c|c|c|c|c|}
\hline Effect & Model & $R^{2}(-)$ & F-Value (-) & $p$-Value (-) \\
\hline \multicolumn{5}{|c|}{ Densification Energy $E N(\mathrm{~J})$} \\
\hline Intercept & 574.98 & & & \\
\hline$F$ & 3.44 & 0.90 & 134.19 & $<0.05$ \\
\hline PS & 14.99 & & & \\
\hline \multicolumn{5}{|c|}{ Hardness $H R\left(\mathrm{kN} \cdot \mathrm{mm}^{-1}\right)$} \\
\hline Intercept & 0.14 & & & $>0.05$ \\
\hline$F$ & 0.01 & 0.97 & 499.04 & $<0.05$ \\
\hline PS & -0.02 & & & $<0.05$ \\
\hline
\end{tabular}

Table 6. Regression results of densification energy and hardness of ground sunflower stalk briquettes with the effects of force and moisture content.

\begin{tabular}{|c|c|c|c|c|}
\hline Effect & Model & $\mathbf{R}^{2}(-)$ & F-Value (-) & $p$-Value (-) \\
\hline \multicolumn{5}{|c|}{ Densification Energy $E N(\mathrm{~J})$} \\
\hline Intercept & 1303.53 & & & \\
\hline$F$ & 2.862 & 0.95 & 199.17 & $<0.05$ \\
\hline$M C$ & -51.44 & & & \\
\hline \multicolumn{5}{|c|}{ Hardness HR $\left(\mathrm{kN} \cdot \mathrm{mm}^{-1}\right)$} \\
\hline Intercept & -0.01 & & & $>0.05$ \\
\hline$F^{1}$ & 0.01 & 0.98 & 685.66 & $<0.05$ \\
\hline$M C$ & 0.001 & & & $>0.05$ \\
\hline
\end{tabular}

\subsection{Deformation, Thickness, Densification Energy and Hardness of Ground Hazelnut Husks Briquettes}

For the ground hazelnut husk briquettes, the values of deformation, thickness, densification energy, and hardness with forces, particle sizes, and moisture contents are given in Tables 7 and 8. Deformation values increased with increased forces and particle sizes, whereas for forces and moisture contents, both increased and decreased amounts were observed. Deformation values ranged from 71.65 to $100.55 \mathrm{~mm}$ for all factors. Briquette thickness decreased along with increased forces and particle sizes, but it increased with forces and moisture contents except for force $100 \mathrm{kN}$, where the values decreased. For the particle size of $3 \mathrm{~mm}$, the thickness values were highest for all forces. Thickness values ranged from 20.18 to $43.81 \mathrm{~mm}$. A similar trend was also observed for the densification energy values, which ranged from 804.11 to 2812.38 J. Hardness values increased along with increased forces but decreased with particle sizes. For forces and moisture contents, the hardness values showed both increasing and decreasing trends. However, for forces 100 and $200 \mathrm{kN}$, the hardness values slightly increased at the particle size of $3 \mathrm{~mm}$. Hardness values ranged from 1.20 to $4.97 \mathrm{kN} \cdot \mathrm{mm}^{-1}$.

The multivariate results of the significance and correlation of the effects of the forces/particle sizes and forces/moisture contents on the densification energy and hardness of ground hazelnut husks are given in Tables 9 and 10. The effects of the forces, particle sizes and moisture contents and their interactions on deformation, thickness, densification energy and hardness were explained based on Wilk's lambda value, F-value, and $p$-value. For all determined parameters, the correlation values for thickness, densification energy, and hardness with forces were higher compared to particle sizes and moisture contents, which showed lower values. 
Table 7. Deformation, thickness, densification energy, and hardness of ground hazelnut husks with forces and particle size.

\begin{tabular}{|c|c|c|c|c|c|}
\hline Force $F(\mathbf{k N})$ & $\begin{array}{l}\text { Particle Size } \\
\text { PS (mm) }\end{array}$ & $\begin{array}{l}\text { Deformation } X \\
(\mathrm{~mm})\end{array}$ & $\begin{array}{c}\text { Thickness TK } \\
\text { (mm) }\end{array}$ & $\begin{array}{l}\text { Densification } \\
\text { Energy } E N(\mathrm{~J})\end{array}$ & $\begin{array}{c}\text { Hardness } H R \\
\left(\mathrm{kN} \cdot \mathrm{mm}^{-1}\right)\end{array}$ \\
\hline \multirow{4}{*}{100} & $* 0$ & $79.28 \pm 0.45$ & $39.75 \pm 0.72$ & $1094.46 \pm 1.03$ & $1.27 \pm 0.01$ \\
\hline & 3 & $71.65 \pm 2.76$ & $43.81 \pm 0.69$ & $1050.07 \pm 6.85$ & $1.40 \pm 0.05$ \\
\hline & 6 & $80.08 \pm 1.75$ & $35.49 \pm 0.26$ & $1031.56 \pm 6.58$ & $1.25 \pm 0.03$ \\
\hline & 10 & $92.42 \pm 0.89$ & $26.69 \pm 1.16$ & $804.11 \pm 5.44$ & $1.08 \pm 0.01$ \\
\hline \multirow{4}{*}{200} & $* 0$ & $79.63 \pm 6.48$ & $33.07 \pm 1.03$ & $1689.61 \pm 31.52$ & $2.53 \pm 0.21$ \\
\hline & 3 & $77.12 \pm 1.78$ & $36.82 \pm 0.82$ & $1750.20 \pm 3.87$ & $2.60 \pm 0.06$ \\
\hline & 6 & $90.10 \pm 6.52$ & $30.41 \pm 0.54$ & $1605.23 \pm 19.86$ & $2.23 \pm 0.16$ \\
\hline & 10 & $93.45 \pm 2.16$ & $22.91 \pm 0.16$ & $1276.39 \pm 8.74$ & $2.15 \pm 0.05$ \\
\hline \multirow{4}{*}{300} & $* 0$ & $79.92 \pm 0.30$ & $31.65 \pm 0.37$ & $2218.97 \pm 7.79$ & $3.75 \pm 0.01$ \\
\hline & 3 & $79.56 \pm 2.38$ & $34.63 \pm 0.08$ & $2307.47 \pm 6.68$ & $3.77 \pm 0.11$ \\
\hline & 6 & $89.98 \pm 6.27$ & $27.78 \pm 0.17$ & $2045.82 \pm 3.85$ & $3.35 \pm 0.23$ \\
\hline & 10 & $100.55 \pm 3.19$ & $20.71 \pm 0.01$ & $1644.56 \pm 14.30$ & $2.99 \pm 0.09$ \\
\hline \multirow{4}{*}{400} & $* 0$ & $80.80 \pm 6.07$ & $30.48 \pm 0.11$ & $2602.32 \pm 50.66$ & $4.97 \pm 0.37$ \\
\hline & 3 & $85.11 \pm 7.42$ & $33.44 \pm 0.32$ & $2812.38 \pm 7.33$ & $4.72 \pm 0.41$ \\
\hline & 6 & $87.39 \pm 1.36$ & $26.61 \pm 0.02$ & $2437.41 \pm 53.60$ & $4.58 \pm 0.07$ \\
\hline & 10 & $97.17 \pm 1.34$ & $20.18 \pm 0.30$ & $2002.76 \pm 76.86$ & $4.12 \pm 0.06$ \\
\hline
\end{tabular}

* 0 (0-10)-control, 3 (3-6), 6 (3-6) and 10 (6-10) $\mathrm{mm}$.

Table 8. Deformation, thickness, energy, and hardness of ground hazelnut husks with forces and moisture contents.

\begin{tabular}{|c|c|c|c|c|c|}
\hline Force $F(\mathbf{k N})$ & $\begin{array}{c}\text { Moisture Content } \\
\text { MC (\% w.b. })\end{array}$ & $\begin{array}{l}\text { Deformation } X \\
\quad(\mathrm{~mm})\end{array}$ & $\begin{array}{l}\text { Thickness TK } \\
\text { (mm) }\end{array}$ & Energy $E N(\mathrm{~J})$ & $\begin{array}{c}\text { Hardness } H R \\
\left(\mathrm{kN} \cdot \mathrm{mm}^{-1}\right)\end{array}$ \\
\hline \multirow{3}{*}{100} & 12.64 & $79.28 \pm 0.45$ & $39.75 \pm 0.72$ & $1094.46 \pm 1.03$ & $1.27 \pm 0.01$ \\
\hline & 14.83 & $76.21 \pm 3.70$ & $38.92 \pm 1.37$ & $992.81 \pm 16.02$ & $1.32 \pm 0.06$ \\
\hline & 17.34 & $83.34 \pm 0.62$ & $38.76 \pm 0.79$ & $926.40 \pm 12.13$ & $1.20 \pm 0.01$ \\
\hline \multirow{3}{*}{200} & 12.64 & $79.63 \pm 6.48$ & $33.07 \pm 1.03$ & $1689.61 \pm 31.52$ & $2.53 \pm 0.21$ \\
\hline & 14.83 & $85.15 \pm 7.30$ & $33.19 \pm 1.32$ & $1581.69 \pm 8.78$ & $2.36 \pm 0.21$ \\
\hline & 17.34 & $77.75 \pm 6.89$ & $34.73 \pm 1.49$ & $1340.72 \pm 55.80$ & $2.58 \pm 0.23$ \\
\hline \multirow{3}{*}{300} & 12.64 & $79.92 \pm 0.30$ & $31.65 \pm 0.37$ & $2218.97 \pm 7.79$ & $3.75 \pm 0.01$ \\
\hline & 14.83 & $79.62 \pm 1.50$ & $32.23 \pm 0.49$ & $1986.39 \pm 51.85$ & $3.77 \pm 0.07$ \\
\hline & 17.34 & $87.20 \pm 0.98$ & $33.78 \pm 1.45$ & $1735.02 \pm 17.29$ & $3.44 \pm 0.04$ \\
\hline \multirow{3}{*}{400} & 12.64 & $80.80 \pm 6.07$ & $30.48 \pm 0.11$ & $2602.32 \pm 50.66$ & $4.97 \pm 0.37$ \\
\hline & 14.83 & $82.65 \pm 0.01$ & $31.74 \pm 0.01$ & $2343.60 \pm 12.22$ & $4.84 \pm 0.00$ \\
\hline & 17.34 & $81.65 \pm 9.74$ & $35.21 \pm 2.79$ & $1875.71 \pm 123.63$ & $4.94 \pm 0.59$ \\
\hline
\end{tabular}

Table 9. ANOVA multivariate tests of significance of parameters of ground hazelnut husk briquettes.

\begin{tabular}{|c|c|c|c|c|c|c|}
\hline Effect & Test & Wilks Value & F-Value (-) & Effect $d f$ & Error $d f$ & $p$-Value (-) \\
\hline \multicolumn{7}{|c|}{ Effects of $F$ and $P S$} \\
\hline Intercept & Wilks lambda & $<0.05$ & $1,705,818$ & 7 & 10.00 & $<0.05$ \\
\hline$F^{1}$ & Wilks lambda & $<0.05$ & 101 & 21 & 29.26 & $<0.05$ \\
\hline$P S$ & Wilks lambda & $<0.05$ & 111 & 21 & 29.26 & $<0.05$ \\
\hline$F \times P S$ & Wilks lambda & $<0.05$ & 4 & 63 & 62.43 & $<0.05$ \\
\hline \multicolumn{7}{|c|}{ Effects of $F$ and $M C$} \\
\hline Intercept & Wilks lambda & $<0.05$ & $1,517,95.7$ & 7 & 6.00 & $<0.05$ \\
\hline$F$ & Wilks lambda & $<0.05$ & 58.6 & 21 & 17.78 & $<0.05$ \\
\hline$M C$ & Wilks lambda & $<0.05$ & 24.7 & 14 & 12.00 & $<0.05$ \\
\hline$F \times M C$ & Wilks lambda & $<0.05$ & 2.9 & 42 & 31.59 & $<0.05$ \\
\hline
\end{tabular}

$F$ : force (kN); PS: particle size (mm); MC: moisture content (\% w.b.); $d f$ : degree of freedom. 
Table 10. Correlation results of parameters against force, particle size, and moisture content of ground hazelnut husk briquettes.

\begin{tabular}{ccccc}
\hline \multirow{2}{*}{ Determined Parameters } & \multicolumn{4}{c}{ Correlation } \\
\cline { 2 - 5 } & $\boldsymbol{F}$ & $\boldsymbol{P S}$ & $\boldsymbol{F R}$ & $\boldsymbol{M C}$ \\
\hline Deformation $(\mathrm{mm})$ & 0.31 & 0.78 & 0.19 & 0.23 \\
Thickness $(\mathrm{mm})$ & -0.49 & 0.73 & -0.76 & 0.25 \\
Densification Energy $(\mathrm{J})$ & 0.92 & 0.31 & 0.92 & -0.34 \\
Analytical Densification Energy $(\mathrm{J})$ & 0.78 & 0.41 & 0.92 & -0.22 \\
Volume $\left(\times 10^{-5} \mathrm{~m}^{3}\right)$ & -0.49 & 0.73 & -0.76 & 0.25 \\
Bulk Density $\left(\mathrm{kg} \cdot \mathrm{m}^{-3}\right)$ & 0.93 & 0.21 & 0.81 & -0.09 \\
Hardness $\left(\mathrm{kN} \cdot \mathrm{mm}^{-1}\right)$ & 0.98 & 0.17 & 0.99 & -0.03 \\
Volume Energy $\left(\times 10^{6} \mathrm{~J} \cdot \mathrm{m}^{-3}\right)$ & 0.98 & 0.14 & 0.89 & -0.36 \\
\hline
\end{tabular}

F: force (kN); PS: particle size (mm); MC: moisture content (\% w.b.).

The regression results of the densification energy and hardness of the densified briquettes from ground hazelnut husks with the effects of forces/particle sizes and forces/moisture contents are also given in Tables 11 and 12. The results in Tables 11 and 12 represent an example of the regression models of the other dependent variables that are highlighted in the discussion section. The suitability of the models was evaluated based on the coefficients of determination $\left(\mathrm{R}^{2}\right)$, F-values, and $p$-values.

Table 11. Regression results of densification energy and hardness of the ground hazelnut husk briquettes with the effects of force and particle size.

\begin{tabular}{|c|c|c|c|c|}
\hline Effect & Model & $R^{2}(-)$ & F-Value (-) & $p$-Value (-) \\
\hline \multicolumn{5}{|c|}{ Densification Energy $E N(\mathrm{~J})$} \\
\hline Intercept & 792.27 & & & \\
\hline$F$ & 4.88 & 0.95 & 273.71 & $<0.05$ \\
\hline$P S$ & -50.29 & & & \\
\hline \multicolumn{5}{|c|}{ Hardness, HR $\left(\mathrm{kN} \cdot \mathrm{mm}^{-1}\right)$} \\
\hline Intercept & 0.41 & & & \\
\hline$F$ & 0.01 & 0.98 & 755.87 & $<0.05$ \\
\hline$P S$ & -0.06 & & & \\
\hline
\end{tabular}

Table 12. Regression results of densification energy and hardness of the ground hazelnut husk briquettes with the effects of force and moisture content.

\begin{tabular}{|c|c|c|c|c|}
\hline Effect & Model & $R^{2}(-)$ & F-Value (-) & $p$-Value (-) \\
\hline \multicolumn{5}{|c|}{ Densification Energy $E N(\mathrm{~J})$} \\
\hline Intercept & 2255.82 & & & \\
\hline$F^{1}$ & 4.25 & 0.95 & 216.22 & $<0.05$ \\
\hline$M C$ & -107.97 & & & \\
\hline \multicolumn{5}{|c|}{ Hardness HR $\left(\mathrm{kN} \cdot \mathrm{mm}^{-1}\right)$} \\
\hline Intercept & 0.37 & & & $>0.05$ \\
\hline$F$ & 0.01 & 0.98 & 557.22 & $<0.05$ \\
\hline$M C$ & -0.02 & & & $>0.05$ \\
\hline
\end{tabular}

$F$ : force (kN); $M C$ : moisture content (\% w.b.). 


\subsection{Effects of Particle Sizes and Moisture Contents on Densification Energy and Hardness of Densified Briquettes}

Comparisons of densification energy and hardness of the densified briquettes of the ground sunflower stalks and hazelnut husks with respect to the processing factors are indicated in Figures 4-7. For all processing factors, briquettes from the ground hazelnut husks required more densification energy than ground sunflower stalk briquettes. Additionally, the hardness of the hazelnut husk briquettes for particle sizes $0-10$ and $0-3 \mathrm{~mm}$ at forces 300 and $400 \mathrm{kN}$ were higher than that of the sunflower stalk briquettes. However, the hardness of the biomass briquettes for particle sizes 3-6 and 6-10 $\mathrm{mm}$ for all forces was similar. This suggests that particle sizes $0-10$ and $0-3 \mathrm{~mm}$ could be used for producing briquettes for energy purposes. The plots of normality of the dataset of energy and hardness are presented in Figure 8, and they are similar to the other determined parameters. It can be seen that the data showed an approximately normal distribution. The normal distribution of the data was also evaluated by the Shapiro-Wilk test [44]. The statistical results, however, are not presented herein.

Wilks lambda $=0.01638, F(36,50.454)=2.7970, \mathrm{p}=0.00040$

Vertical bars denote 0.95 confidence intervals

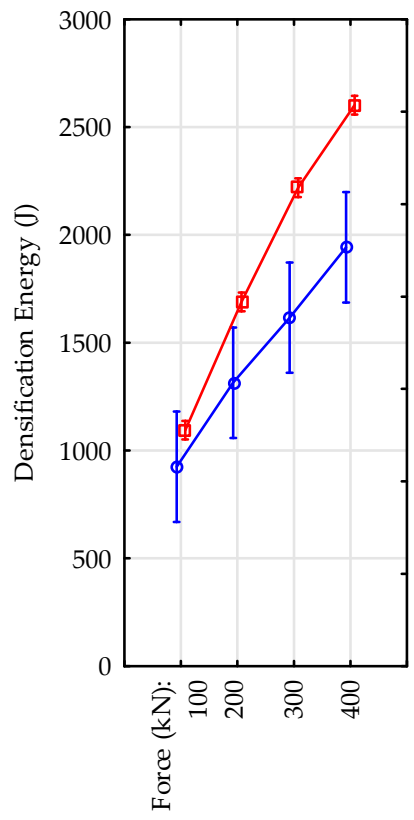

Particle size: $0(0-10 \mathrm{~mm})$

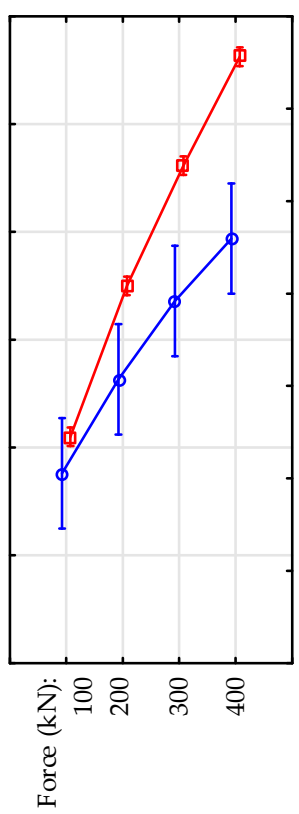

Particle size: $3(0-3 \mathrm{~mm})$
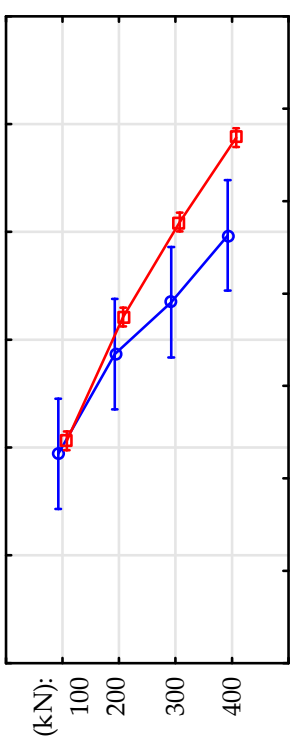

है

Particle size: $6(3-6 \mathrm{~mm})$

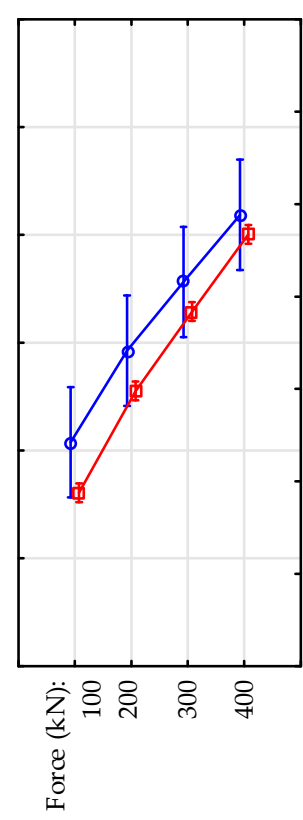

Particle size:

$10(6-10 \mathrm{~mm})$

画 Ground sunflower stalks briquettes $\overline{\text { 业 }}$ Ground hazelnut husks briquettes

Figure 4. Effects of forces and particle sizes on briquette densification energy. 
Wilks la mbda $=0.04136, \mathrm{~F}(12,22)=7.1818, \mathrm{p}=0.00004$

Vertical bars denote 0.95 confidence intervals

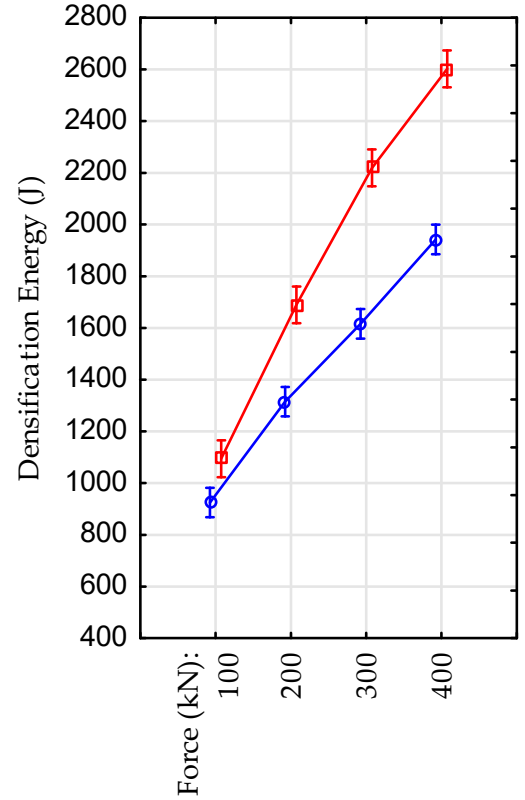

Moisture content: 12 (\% w.b.)

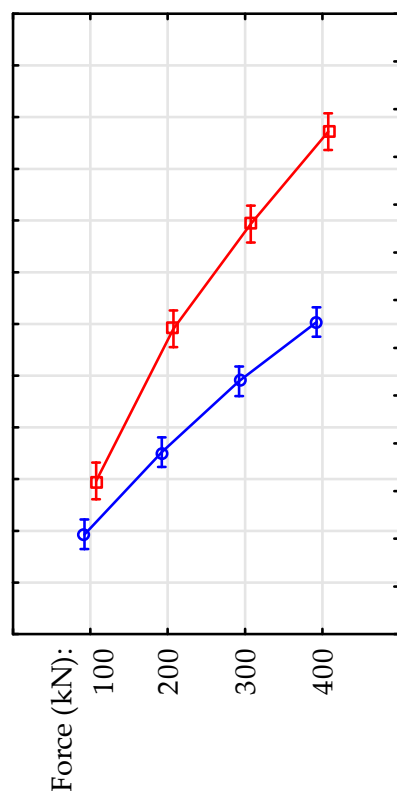

Moisture content: 14 (w.b.)

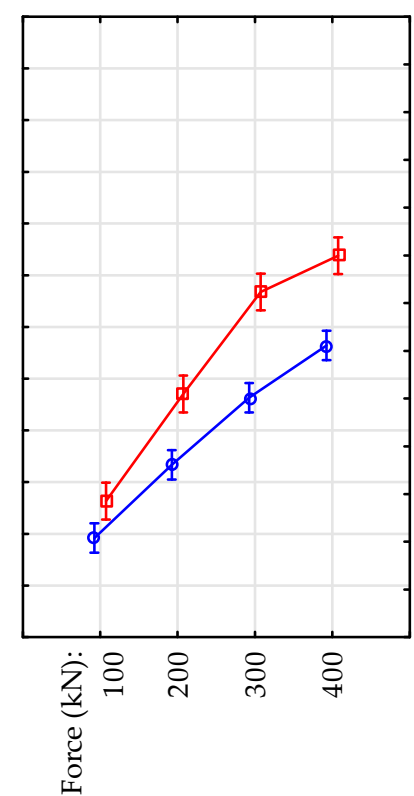

Moisture content: 17 (\% w.b.)

$\Phi$ Ground sunflower stalks briquettes Ground hazelnut husks briquettes

Figure 5. Effects of forces and moisture contents on briquette densification energy.

Wilks lambda $=0.01638, F(36,50.454)=2.7970, \mathrm{p}=0.00040$

Vertical bars denote 0.95 confidence intervals

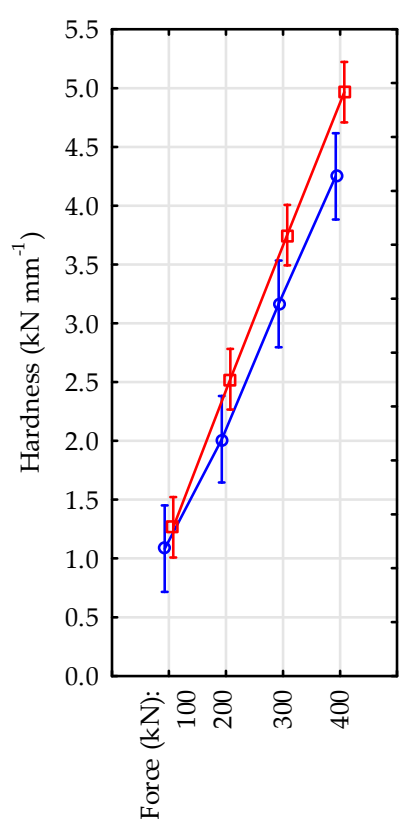

Particle size: $0(0-10 \mathrm{~mm})$

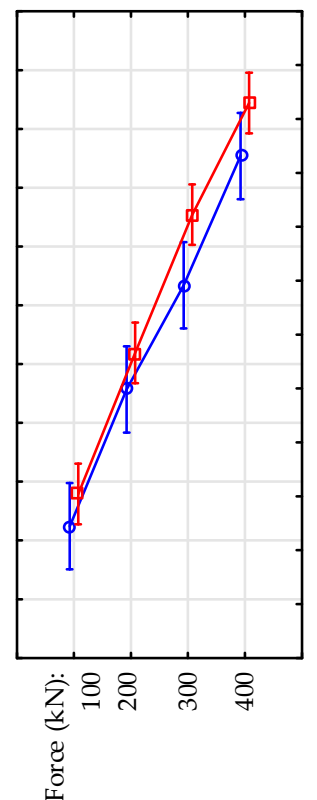

Particle size: $3(0-3 \mathrm{~mm})$
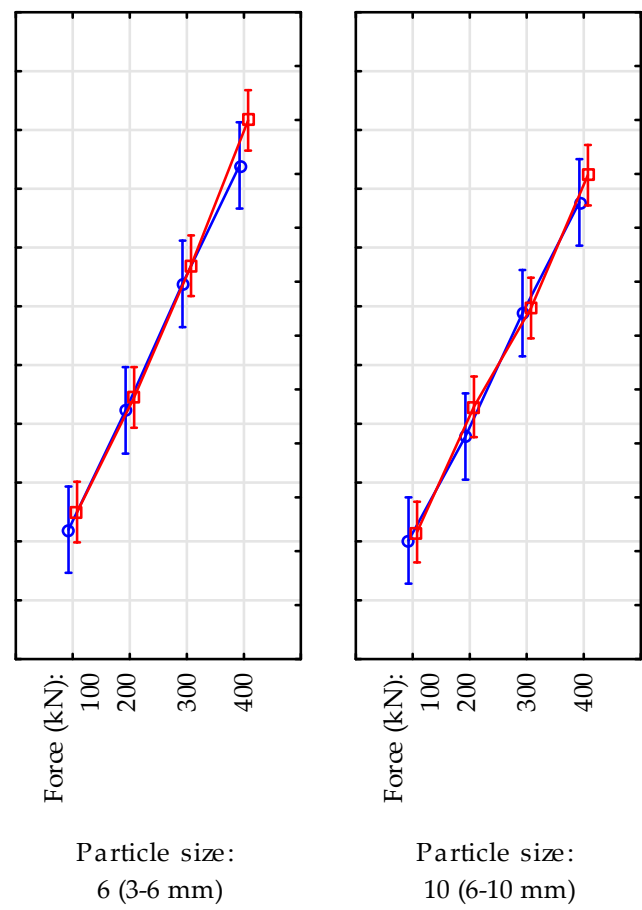

Particle size: $10(6-10 \mathrm{~mm})$

Ð Ground sunflower stalks briquettes $\overline{\text { 車 }}$ Ground hazelnut husks briquettes

Figure 6. Effects of forces and particle sizes on briquette hardness. 
Wilks la mbda $=0.00841, F(24,32.607)=3.9864, \mathrm{p}=0.00015$

Vertical bars denote 0.95 confidence intervals

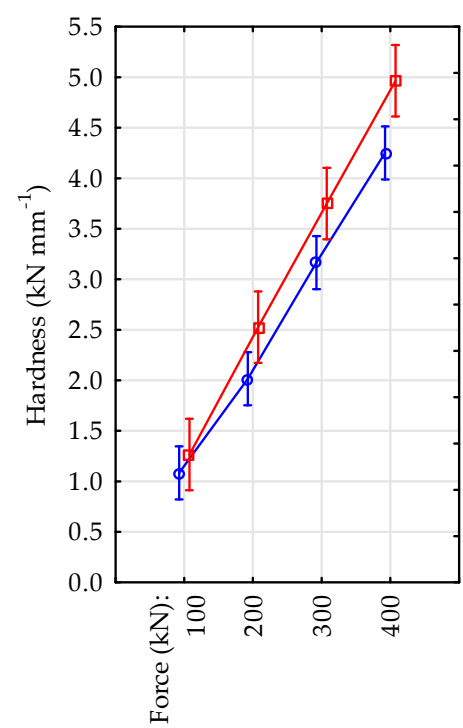

Moisture content: 12 (\% w.b.)

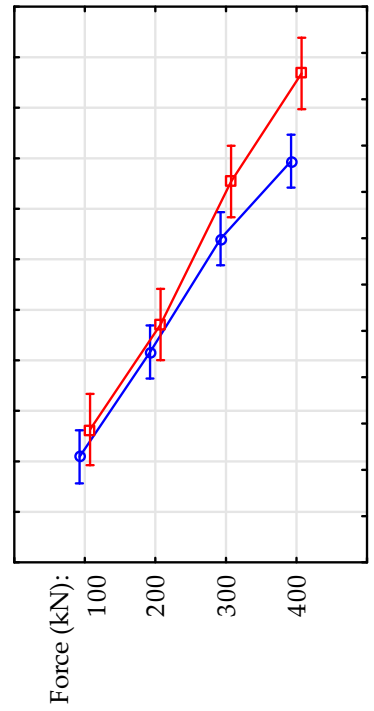

Moisture content: 14 (\% w.b.)

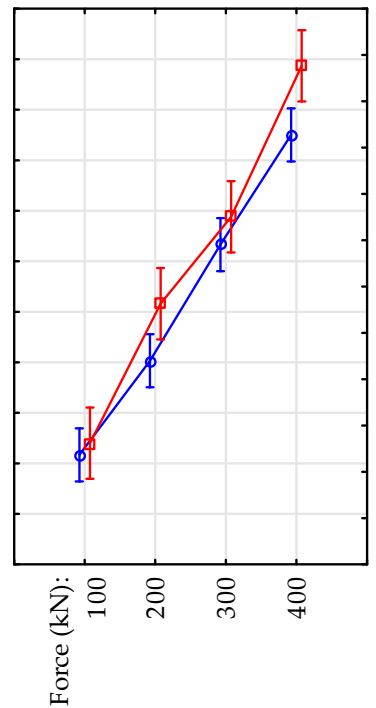

Moisture content: 17 (\% w.b.)

Ф Ground sunflower stalks briquettes $\overline{\text { 曺 }}$ Ground hazelnut husks briquettes

Figure 7. Effects of forces and moisture contents on briquette hardness.
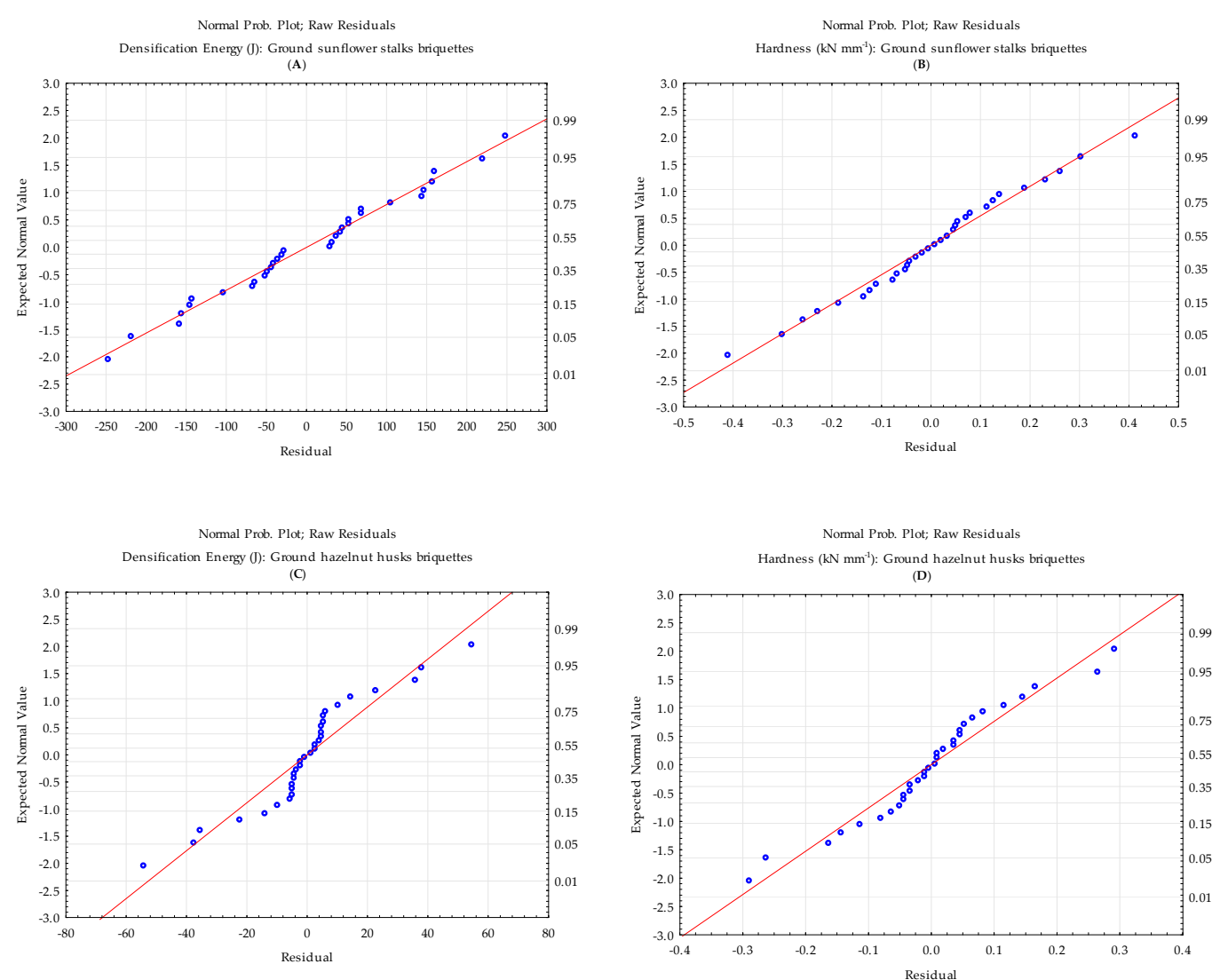

Figure 8. Normal probability plots of densification energy (A) and hardness (B) of ground sunflower stalk, and densification energy (C) and hardness (D) of ground hazelnut husk briquettes under the effects of forces and particle sizes similar to other determined parameters. 


\subsection{Description of Analytical Densification Energy of Biomass Briquettes}

The densification energies of the ground sunflower stalk and hazelnut husk briquettes were theoretically described, and the results are given in Tables 13 and 14. The experimental and theoretical curves of particle sizes and moisture contents at a maximum force of $400 \mathrm{kN}$ are illustrated in Figures 9 and 10. The analytical densification energy for the ground sunflower stalk briquettes for forces and particle sizes ranged from 799.33 to $2391.98 \mathrm{~J}$, and for forces and moisture contents, the values ranged from 589.92 to $2536.52 \mathrm{~J}$. At forces 200 and $300 \mathrm{kN}$ for particle sizes 6 and $10 \mathrm{~mm}$, as well as moisture contents $14.44 \%$ and $16.89 \%$ w.b., the data points were further apart compared to the densification energies. For ground hazelnut husk briquettes, the analytical energies for forces and particle sizes ranged from 657.63 to $3376.84 \mathrm{~J}$, whereas for forces and moisture contents, the values ranged from 748.60 to $3427.44 \mathrm{~J}$. At force $300 \mathrm{kN}$ for particle sizes $0-10 \mathrm{~mm}$ (the control) and forces 300 and $400 \mathrm{kN}$ at moisture contents $12.64 \%$ and $17.34 \%$ w.b., the theoretical data points were very different in comparison with the experimental values. This could have been due to the air spaces and friction between the bulk biomass materials and the walls of the pressing vessel during the densification process. The use of binders such as cassava starch wastewater, rice dust, and okra stem gum [25] could ensure effective compaction for the accurate theoretical description of the experimental data.

Table 13. Analytical densification energy of ground sunflower stalks and hazelnut husks at moisture contents of $11.23 \%$ and $12.64 \%$ w.b.

\begin{tabular}{cccc}
\hline \multirow{2}{*}{ Force $\boldsymbol{F}(\mathbf{k N})$} & Particle Size PS $(\mathbf{m m})$ & \multicolumn{2}{c}{ Analytical Densification Energy $\boldsymbol{A E} \mathbf{( J )}$} \\
\cline { 2 - 4 } & & $\begin{array}{c}\text { Ground Sunflower } \\
\text { Stalk Briquettes }\end{array}$ & $\begin{array}{c}\text { Hazelnut Husk } \\
\text { Briquettes }\end{array}$ \\
\hline \multirow{3}{*}{100} & $* 0$ & $830.80 \pm 121.6$ & $948.93 \pm 9.90$ \\
& 3 & $799.63 \pm 146.54$ & $963.83 \pm 73.87$ \\
& 6 & $1072.12 \pm 179.14$ & $1009.98 \pm 167.98$ \\
10 & $878.64 \pm 118.47$ & $657.63 \pm 52.44$ \\
\hline \multirow{3}{*}{200} & $* 0$ & $1614.12 \pm 493.71$ & $1476.58 \pm 114.49$ \\
& 3 & $1212.15 \pm 192.61$ & $1741.12 \pm 288.89$ \\
& 6 & $1500.36 \pm 41.95$ & $1460.79 \pm 217.01$ \\
& 10 & $892.07 \pm 13.43$ & $1301.10 \pm 367.25$ \\
\hline \multirow{3}{*}{300} & $* 0$ & $1360.17 \pm 470.35$ & $2892.48 \pm 112.92$ \\
& 3 & $1416.873 \pm 86.28$ & $2332.56 \pm 326.83$ \\
6 & $1201.46 \pm 324.27$ & $2045.30 \pm 624.73$ \\
& 10 & $1560.88 \pm 679.50$ & $1386.11 \pm 514.52$ \\
\hline & $* 0$ & $2318.85 \pm 511.33$ & $3097.17 \pm 280.00$ \\
& 3 & $2391.98 \pm 519.70$ & $3376.84 \pm 218.21$ \\
& 6 & $1541.78 \pm 266.91$ & $2318.94 \pm 712.73$ \\
& 10 & $1903.98 \pm 419.61$ & $1629.64 \pm 445.34$ \\
\hline
\end{tabular}

* 0 (0-10)-control, 3 (3-6), 6 (3-6) and 10 (6-10) $\mathrm{mm}$.

Table 14. Analytical densification energy of ground sunflower stalks and hazelnut husks for particle sizes $0-10 \mathrm{~mm}$.

\begin{tabular}{cccc}
\hline \multirow{2}{*}{ Force $\boldsymbol{F}(\mathbf{k N})$} & $\begin{array}{c}\text { Moisture Content } M C \\
\text { (\% w.b.) }\end{array}$ & $\begin{array}{c}\text { Ground Sunflower } \\
\text { Stalks Briquettes }\end{array}$ & $\begin{array}{c}\text { Ground Hazelnut } \\
\text { Husks Briquettes }\end{array}$ \\
\cline { 3 - 4 } & $14.44^{\mathrm{a}}(14.83)^{\mathrm{b}}$ & $695.53 \pm 187.54^{\mathrm{a}}$ & $1039.33 \pm 21.27^{\mathrm{b}}$ \\
\hline \multirow{2}{*}{100} & $16.89^{\mathrm{a}}(17.34)^{\mathrm{b}}$ & $589.92 \pm 62.52^{\mathrm{a}}$ & $748.60 \pm 50.37^{\mathrm{b}}$ \\
\hline \multirow{2}{*}{200} & $14.44^{\mathrm{a}}(14.83)^{\mathrm{b}}$ & $606.22 \pm 34.69^{\mathrm{a}}$ & $1629.72 \pm 479.32^{\mathrm{b}}$ \\
& $16.89^{\mathrm{a}}(17.34)^{\mathrm{b}}$ & $1340.93 \pm 1004.64^{\mathrm{a}}$ & $1115.33 \pm 3.49^{\mathrm{b}}$ \\
\hline
\end{tabular}


Table 14. Cont.

\begin{tabular}{|c|c|c|c|}
\hline \multirow{2}{*}{ Force $F(\mathbf{k N})$} & \multirow{2}{*}{$\begin{array}{l}\text { Moisture Content } M C \\
\text { (\% w.b.) }\end{array}$} & \multicolumn{2}{|c|}{ * Analytical Densification Energy $A E(J)$} \\
\hline & & $\begin{array}{l}\text { Ground Sunflower } \\
\text { Stalks Briquettes }\end{array}$ & $\begin{array}{l}\text { Ground Hazelnut } \\
\text { Husks Briquettes }\end{array}$ \\
\hline \multirow{2}{*}{300} & $14.44^{\mathrm{a}}(14.83)^{\mathrm{b}}$ & $1361.89 \pm 562.43^{a}$ & $2046.46 \pm 318.29^{b}$ \\
\hline & $16.89^{a}(17.34)^{b}$ & $2536.52 \pm 670.48^{\mathrm{a}}$ & $2197.08 \pm 370.86^{b}$ \\
\hline \multirow{2}{*}{400} & $14.44^{\mathrm{a}}(14.83)^{\mathrm{b}}$ & $1750.59 \pm 784.10^{a}$ & $3427.44 \pm 113.30^{b}$ \\
\hline & $16.89^{a}(17.34)^{b}$ & $1698.35 \pm 16.87^{\mathrm{a}}$ & $2444.56 \pm 110.08^{b}$ \\
\hline
\end{tabular}

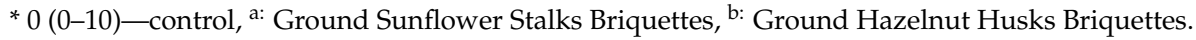

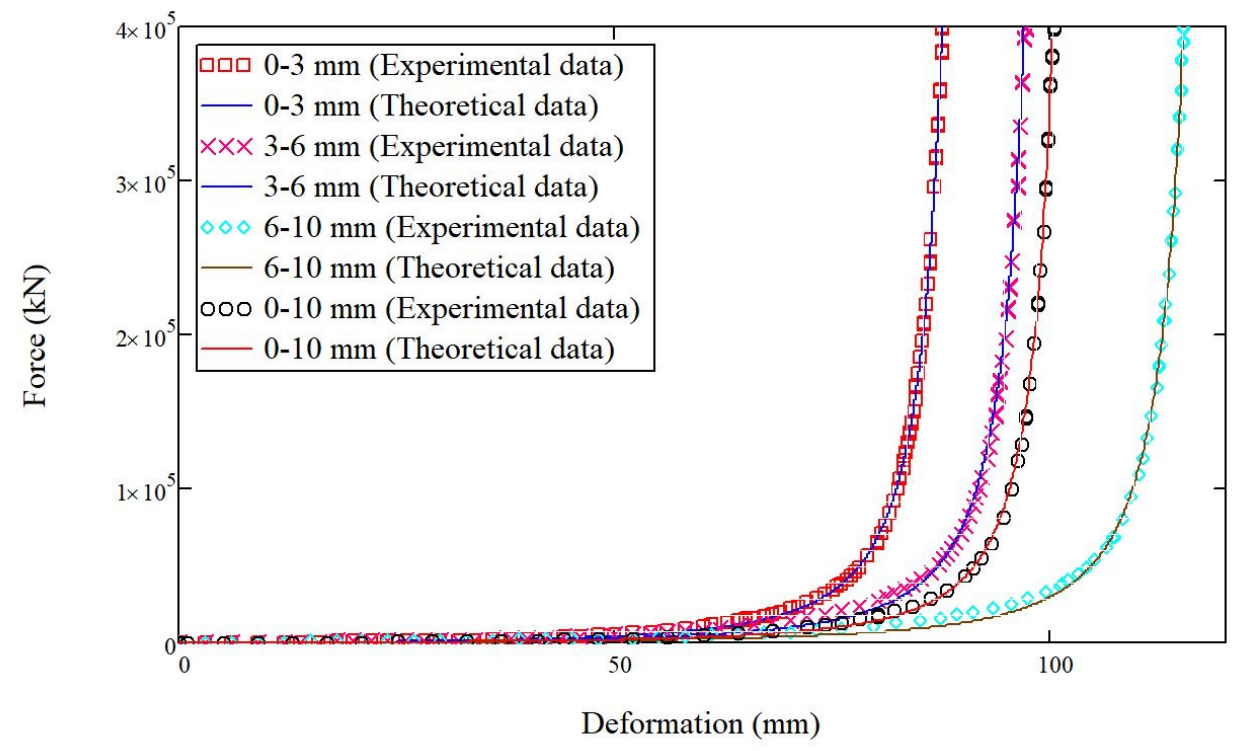

Figure 9. Force-deformation curves of ground sunflower stalk briquettes for particle sizes at a moisture content of $11.23 \%$ w.b.

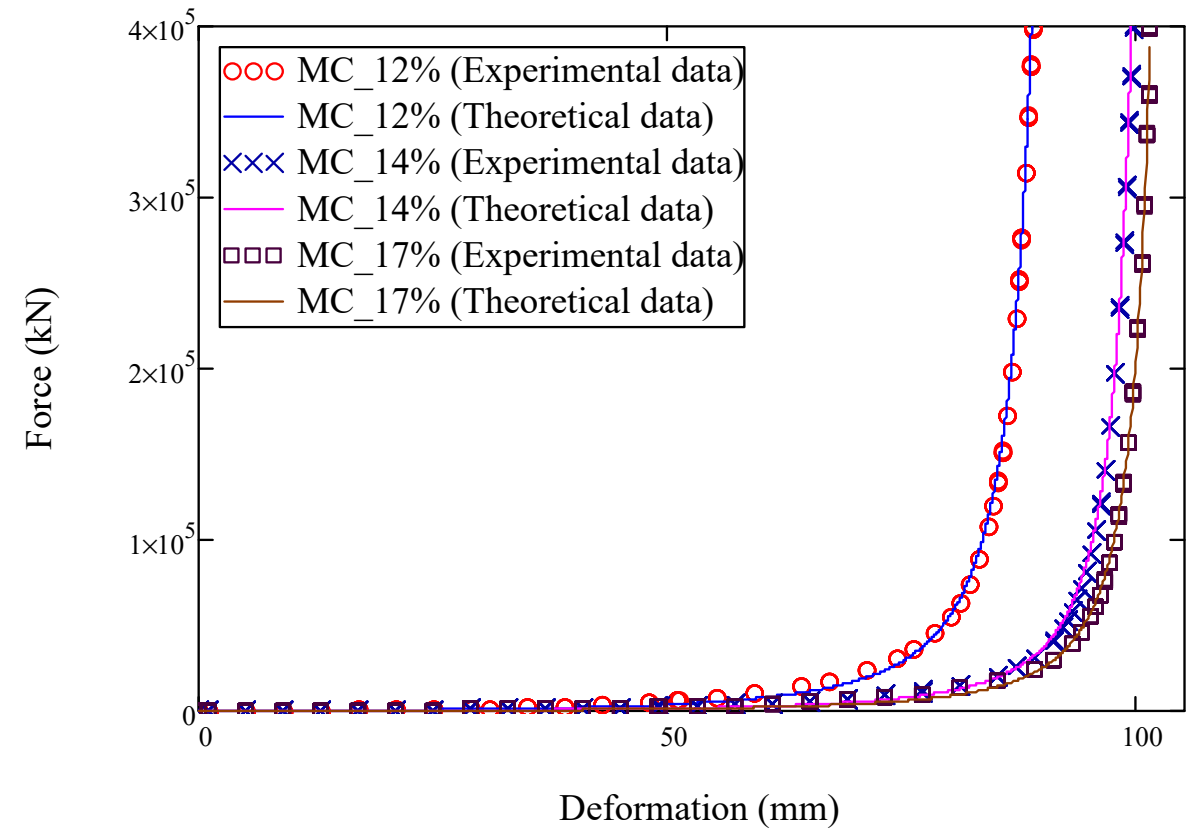

Figure 10. Force-deformation curves of ground sunflower stalk briquettes at different moisture contents for the particle size of $0(0-10) \mathrm{mm}$. 


\subsection{Other Calculated Parameters of Densified Biomass Briquettes (Supplementary Material)}

The coefficients of the tangent model (the force coefficient of mechanical behaviour $(\mathrm{kN})$, the deformation coefficient of mechanical behaviour $(\mathrm{mm})$, and the fitting value $(-))$ and their statistical results for describing the theoretical/analytical force-deformation curves and densification energies (as well as the experimental calculation of the briquette volume, bulk density, and volume energy) are presented in the Supplementary Materials Tables S1-S8 and Figures S1-S3, respectively. For the forces, particle sizes, and moisture contents of the ground sunflower stalk briquettes, the force coefficients of the mechanical behaviour ranged from 1.256 to $3.575 \mathrm{kN}$, while the deformation coefficients of mechanical behaviour ranged from 0.014 to $0.017 \mathrm{~mm}^{-1}$. On the other hand, for the forces, particle sizes, and moisture contents of the ground hazelnut husk briquettes, the force coefficients of the mechanical behaviour ranged from 2.477 to $24.765 \mathrm{kN}$, while the deformation coefficients ranged from 0.015 to $0.019 \mathrm{~mm}^{-1}$. The fitting curve exponent of the model was found to be $2(-)$, with a high coefficient of determination $\left(\mathrm{R}^{2}\right)$ of $99 \%$. The briquette volume decreased along with the increased forces for each particle size and moisture content. However, both increasing and decreasing trends of the volume with particle sizes and moisture contents were noticed for all forces. The polynomial function of $\left(R^{2}\right)$ values between 0.87 and 0.97 suitably described the relationships between briquette volumes and forces, particle sizes, and moisture contents. For all the predictors, the briquette volume from the sunflower stalks ranged from 5.22 to $7.73 \times 10^{-5} \mathrm{~m}^{3}$ and that of the hazelnut husk briquettes ranged from 5.70 to $11.24 \times 10^{-5} \mathrm{~m}^{3}$. The bulk density of the briquettes increased along with forces for each particle size and moisture content, but it generally decreased for varying particle sizes and moisture contents at a specific force. The polynomial function of $\left(R^{2}\right)$ values between 0.66 and 0.93 adequately described the relationships between briquette density and forces, particle sizes, and moisture contents. The bulk density of ground sunflower stalk briquettes ranged from 653.29 to $964.41 \mathrm{~kg} \cdot \mathrm{m}^{-3}$, and that of the ground hazelnut husk briquettes ranged from 765.60 to $1056.69 \mathrm{~kg} \cdot \mathrm{m}^{-3}$ with respect to the predictors. The briquette volume energy increased along with forces and particle sizes, but it decreased with moisture contents. The polynomial function of $\left(R^{2}\right)$ values between 0.82 and 1 satisfactorily described the relationships between briquette volume energy and forces, particle sizes, and moisture contents. Ground sunflower stalk briquette volume energy ranged from 10.14 to $39.68 \times 10^{-6} \mathrm{~J} \cdot \mathrm{m}^{-3}$, and that of ground hazelnut husk briquettes ranged from 8.48 to $35.12 \times 10^{-6} \mathrm{~J} \cdot \mathrm{m}^{-3}$ in relation to the predictors.

\section{Discussion}

The determined parameters (responses) from the densification tests of the ground sunflower stalk and hazelnut husk briquettes under different processing factors (forces, particle sizes, and moisture contents) were densification energy $(\mathrm{J})$, hardness $\left(\mathrm{kN} \cdot \mathrm{mm}^{-1}\right)$, analytical densification energy $(\mathrm{J})$, briquette volume $\left(\mathrm{m}^{3}\right)$, bulk density of materials $\left(\mathrm{kg} \cdot \mathrm{m}^{-3}\right)$, briquette bulk density $\left(\mathrm{kg} \cdot \mathrm{m}^{-3}\right)$, and briquette volume energy $\left(\mathrm{J} \cdot \mathrm{m}^{-3}\right)$. The densification curves and energies were theoretically described using the tangent curve model.

For the ground sunflower stalk briquettes, the ANOVA multivariate tests of significance of the effect of the forces and particle sizes on the responses were significant $(p<0.05)$. The interaction effect of the force and particle size on the above-mentioned parameters was not significant $(p>0.05)$. However, based on the univariate results, force did not have significant effect on deformation. The particle size effect was only significant on bulk density and volume energy. In addition, the multivariate tests of significance of the effects of the forces and moisture contents and their interactions on the responses proved significant. Nevertheless, the univariate results showed that only moisture content had a significant effect on deformation. Moisture content and the interactions of force and moisture content also had no significant effects on analytical densification energy and hardness. The correlation between force and the dependent variables was significant, except for deformation, which was not significant. On the other hand, deformation only correlated significantly with particle size and moisture content compared to the other responses, which showed non-significant correlations. The regression results showed that the coefficients of the force and particle size on the models for densification energy, 
hardness, and volume energy were significant $(p<0.05)$; only the coefficients of the particle size were significant for the thickness, analytical energy, briquette volume, and bulk density models; and for deformation, only the force coefficient was significant. In addition, for the regression results of the interactions of force and moisture content, the coefficients of the force and moisture content were significant for thickness, densification energy, briquette volume, and volume energy. The models for deformation, analytical densification energy, bulk density, and briquette hardness showed only the force coefficients as being significant.

For the ground hazelnut husk briquettes, the ANOVA multivariate tests of significance of the effects of forces, particle sizes, moisture contents, and their interactions with the above-mentioned responses were significant $(p<0.05)$. However, the univariate results showed that the interaction effect of force and particle size on deformation, analytical densification energy, bulk density, and hardness was not significant $(p>0.05)$. The effects of force, moisture content, and interactions on deformation were not significant, but those of densification energy, analytical energy and volume energy were significant. The interaction effects of force and moisture content on thickness and briquette volume were not significant. Briquette bulk density and hardness showed that moisture content, as well as force and moisture content interactions, were non-significant. The correlation between deformation, force, and moisture content were non-significant, similar to the results of ground sunflower stalk briquettes. Densification energy, bulk density, hardness, and volume energy did not significantly correlate with particle size compared to thickness, analytical densification energy, and briquette volume which significantly correlated with particle size. There was no significant correlation between the dependent variables and moisture content. The coefficients of the factors (force and particle size) in the regression models describing all the responses of the ground hazelnut husk briquettes were significant compared to the processing factors (force and moisture content), where only the densification energy, analytical energy, and volume energy were significant. For deformation, all the predictors were not significant, whereas only the moisture content predictor was not significant for thickness, hardness, briquette volume, and bulk density.

Generally, based on the test of the sum of squares whole model against the sum of squares residual model, the factors/predictors had a significant effect on all the responses except for deformation, where the combined effect of force/moisture content and force/particle size had no significant effect. The coefficients of determination $\left(\mathrm{R}^{2}\right)$ of the regression models ranged between $30 \%$ and $98 \%$.

Furthermore, the densification energy of the briquettes was determined from the area under the force and deformation (densification) curves. Using the tangent curve model [28,40-43], the analytical energy was determined. It is important to state that the application of the tangent model took the physical principles of the uniaxial compression process into account; these principle are that zero force means zero deformation, increasing force causes deformation to reach a maximum limit, and the integral of the force as a function of deformation from the zero to the maximum limit is the energy (that is, the densification energy for biomass materials and deformation energy in the case of bulk oilseeds). The ANOVA results of the tangent model coefficients were significant where the F-critical values were higher than the F-ratio values and/or $p$-values greater than the alpha level of 0.05 , thus confirming the suitability of the tangent curve model for describing the uniaxial compression data.

In the literature, the authors of [29] explained that at low forces, straw bales had a small stiffness that changed with the applied force and the behaviour was almost linear; as the load increased further, a stiffening behaviour was realized. Additionally, the authors of [1] reported that the density of the compacted biomass briquettes from barley, oat, canola, and wheat straw increased with increasing pressure and moisture content. The authors of [8] highlighted that the briquette density of corn stover increased with pressure, whereas low moisture content between $5 \%$ and $10 \%$ (w.b.) resulted in denser, more stable, and more durable briquettes than the high moisture corn stover content of $15 \%$ (w.b.). In a separate study by the authors of [32], the pellet density of wheat straw, barley straw, corn stover, and switchgrass increased as compressive pressure increased at a sample particle size of $3.2 \mathrm{~mm}$ and a moisture content of $12 \%$ (w.b.). The authors of [44] also mentioned that increased particle size and 
moisture content decreased the durability of cassava stalk pellets. Additionally, our previous study [28] showed that densified briquettes from jatropha seedcake with a particle size of $10 \mathrm{~mm}$ recorded the minimum energy followed by the particle size of $6.7 \mathrm{~mm}$. However, the hardness of the briquettes at a maximum force of $400 \mathrm{kN}$ (pressure of $141.47 \mathrm{MPa}$ ) was achieved at a particle size of $6.7 \mathrm{~mm}$ followed by the particle size of $5.6 \mathrm{~mm}$. Finally, the authors of [45] stated that corn stover feedstock moisture $<34 \%$ (w.b.) and preheating $>70{ }^{\circ} \mathrm{C}$ increased the density and durability of the pellets. The results of the present study are in agreement with published studies on different biomass materials and thus prove the scientific relevance of the work and provide an important contribution to the literature.

\section{Conclusions}

The effects of processing factors (forces, particle sizes, and moisture contents) on the mechanical behaviour of ground sunflower stalk and hazelnut husk briquettes were studied under uniaxial compression loading. ANOVA multivariate tests of significance, univariate tests, correlation and regression analyses, and normality tests were used to evaluate the statistical significance of the responses. The experimental data (densification curves and energies) were theoretically described using the tangent model by determining the force coefficient of the mechanical behaviour, the deformation coefficient of mechanical behaviour, and the fitting curve value. The coefficients of the model were statistically significant with a high coefficient of determination of $99 \%$. The test of the sum of squares whole model against the sum of squares residual model of the regression analysis showed that the processing factors had a significant effect on all the responses except for deformation, where the combined effect of the force and moisture content and the force and particle size had no significant effect. The coefficients of determination $\left(\mathrm{R}^{2}\right)$ of the established regression models ranged between $30 \%$ and $98 \%$. The hardness of ground sunflower stalk and hazelnut husk briquettes was achieved at a higher force of $400 \mathrm{kN}$ and particle sizes of 0-10 $\mathrm{mm}$, altogether, and/or 0-3 $\mathrm{mm}$ at the moisture contents of $11.23 \%$ and $12.64 \%$ w.b., respectively. The optimum densification energy and hardness values of the ground sunflower stalk briquettes was between $1942.61 \pm 72.22$ and $1969.24 \pm 52.88 \mathrm{~J}$ and between $4.25 \pm 0.36$ and $4.27 \pm 0.42 \mathrm{kN} / \mathrm{mm}$. For the ground hazelnut husk briquettes, the optimum densification energy and hardness values were between $2602.32 \pm 50.66$ and $2812.38 \pm 7.33 \mathrm{~J}$ and between $4.72 \pm 0.41 \mathrm{kN} / \mathrm{mmand} 4.97 \pm 0.37 \mathrm{kN} / \mathrm{mm}$. The briquette volume decreased along with increased forces for each particle size and moisture content. The bulk density of the briquettes increased along with forces for each particle size and moisture content, but it generally decreased for varying particle sizes and moisture contents at a specific force. The briquette volume energy increased along with forces and particle sizes, but it decreased with moisture contents.

Briquette production from ground sunflower stalks and hazelnut husks could be also attractive for the briquette market. However, binding additives such as cassava starch wastewater, rice dust, and okra stem gum, as well as pre-treatment methods and response surface designs of experiments should be considered in future research to fully understand the mechanical behaviour of the studied biomass materials, among others, to determine the optimum processing conditions for briquette production.

Supplementary Materials: The following are available online at http://www.mdpi.com/1996-1073/13/10/2542/s1, Table S1: Determined tangent curve model coefficients and statistical analysis of ground sunflower stalks briquettes of $11.23 \%$ (w.b.), Table S2: Determined tangent curve model coefficients and statistical analysis of densified briquettes of ground sunflower stalks for particle size 0-10 mm, Table S3: Determined tangent curve model coefficients and statistical analysis of ground hazelnut husks briquettes of 12.64 (\% w.b.), Table S4: Determined tangent curve model coefficients and statistical analysis of densified briquettes of ground hazelnut husks for particle size of $0(0-10) \mathrm{mm}$ (control), Table S5: Ground sunflower stalks briquette volume, bulk density and volume energy at moisture content of $11.23 \%$ (w.b.), Table S6: Ground sunflower stalks briquette volume, bulk density and volume energy at particle size of $0(0-10) \mathrm{mm}$ (control), Table S7: Ground hazelnut husks briquette volume, bulk density and volume energy at moisture content of $12.64 \%$ (w.b.), Table S8: Ground hazelnut husks briquette volume, bulk density and volume energy at particle size of $0(0-10) \mathrm{mm}$ (control), Figure S1: Normal probability plots of densification energy and hardness of ground sunflower stalks and hazelnut husks briquettes under the effects of force and moisture content similar to other determined parameters, Figure S2: Force-deformation curves of ground hazelnut husks particle sizes at moisture content of $12.64 \%$ (w.b.) and Figure S3: Force-deformation curves of ground hazelnut husks at different moisture content for particle size of $0(0-10) \mathrm{mm}$. 
Author Contributions: Conceptualization, G.A.K.G., D.H., and C.D.; funding acquisition, G.A.K.G.; methodology, C.D., G.A.K.G., and A.K.; data curation, C.D. and A.K.; writing-original draft, C.D., G.A.K.G., A.K., and D.H.; writing-review and editing, C.D., G.A.K.G., A.K., and D.H. All authors have read and agreed to the published version of the manuscript.

Funding: This study was funded by the Scientific and Technological Research Council of Turkey (TÜBİTAK), TÜBİTAK BIDEB 2214-A Doctoral Research Fellowship Program at Abroad with the number 1059B141700726.

Conflicts of Interest: The authors declare no conflict of interest.

\section{References}

1. Guo, L.; Wang, D.; Tabil, L.G.; Wang, G. Compression and relaxation properties of selected biomass for briquetting. Biosyst. Eng. 2016, 148, 101-110. [CrossRef]

2. Mikulandric, R.; Vermeulen, B.; Nicolai, B.; Saeys, W. Modelling of thermal processes during extrusion based densification of agricultural biomass residues. Appl. Energy 2016, 184, 1316-1331. [CrossRef]

3. Adapa, P.; Tabil, L.; Schoenau, G. Compression characteristics of selected ground agricultural biomass. Agric. Eng. Int. CIGR J. 2009, 9, 1-19.

4. Rajaseenivasan, T.; Srinivasan, V.; Qadir, G.S.M.; Srithar, K. An investigation on the performance of sawdust briquette with neem powder. Alex. Eng. J. 2016, 55, 2833-2838. [CrossRef]

5. Van Pelt, T.J. Maize, soybean, and alfalfa biomass densification. Agric. Eng. Int. CIGR J. 2003, 5, 1-17.

6. Muazu, R.I.; Borrion, A.L.; Stegemann, J.A. Life cycle assessment of biomass densification systems. Biomass Bioenergy 2017, 107, 384-397. [CrossRef]

7. Shaw, M.D.; Tabil, L.G. Compression, relaxation and adhesion properties of selected biomass grinds. Agric. Eng. Int. CIGR J. 2007, 9, 1-15.

8. Mani, S.; Tabil, L.G.; Sokhansanj, S. Specific energy requirement for compacting corn stover. Bioresour. Technol. 2006, 97, 1420-1426. [CrossRef]

9. Sokhansanj, S.; Mani, S.; Bi, X.T.; Zaini, P.; Tabil, L. Binderless Pelletization of Biomass; ASAE Paper No. 056061; ASABE: St. Joseph, MI, USA, 2005; p. 1.

10. Li, Y.; Liu, H. High-pressure densification of wood residues to form an upgraded fuel. Biomass Bioenergy 2000, 19, 177-186. [CrossRef]

11. Gilvari, H.; de Jong, W.; Schott, D.L. Quality parameters relevant for densification of bio-materials: Measuring methods and affecting factors-A review. Biomass Bioenergy 2019, 120, 117-134. [CrossRef]

12. Balatinecz, J.J. The potential role of densification in biomass utilization. Biomass Utilization 1983, 67, 181-190.

13. Kaliyan, N.; Morey, R.V. Constitutive model for densification of corn stover and switchgrass. Biosyst. Eng. 2009, 104, 47-63. [CrossRef]

14. Mani, S.; Tabil, L.G.; Sokhansanj, S. Compaction behavior of some biomass grinds. In AIC Meeting; Saskatchewan AIC Paper No. 02-305; CSAE/SCGR Program: Saskatoon, SK, Canada, 2002.

15. Faborode, M.O.; O'Callaghan, J.R. A rheological model for the compaction of fibrous agricultural materials. J. Agric. Eng. Res. 1989, 42, 165-178. [CrossRef]

16. Faborode, M.O.; O'Callaghan, J.R. Optimizing the compression/briquetting of fibrous agricultural materials. J. Agric. Eng. Res. 1987, 38, 245-262. [CrossRef]

17. Mani, S.; Tabil, L.G.; Sokhansanj, S. An overview of compaction of biomass grinds. Powder Handl. Process 2003, 15, 160-168.

18. Cooper, A.R.; Eaton, L.E. Compaction behavior of several ceramic powders. J. Am. Ceram. Soc. 1962, 45, 97-101. [CrossRef]

19. Nona, K.D.; Lenaerts, B.; Kayacan, E.; Saeys, W. Bulk compression characteristics of straw and hay. Biosyst. Eng. 2014, 118, 194-202. [CrossRef]

20. Adeleke, A.A.; Odusote, J.K.; Lasode, O.A.; Ikubanni, P.P.; Malathi, M.; Paswan, D. Densification of coal fines and mildly torrefied biomass into composite fuel using different organic binders. Heliyon 2019, 5, e02160. [CrossRef]

21. Frodeson, S.; Henriksson, G.; Berghel, J. Effects of moisture content during densification of biomass pellets, focusing on polysaccharide substances. Biomass Bioenergy 2019, 122, 322-330. [CrossRef] 
22. Oliveira, H.R.; Bassin, I.D.; Cammarota, M.C. Bioflocculation of cynobacteria with pellets of Aspergillus niger: Effects of carbon supplementation, pellet diameter, and other factors in biomass densification. Bioresour. Technol. 2019, 294, 122167. [CrossRef]

23. Zvicevičius, E.; Raila, A.; Čipliene, A.; Černiauskiene, Z.; Kadžiuliene, Z.; Tilvikiene, V. Effects of moisture and pressure on densification process of raw material from Artemisia dubia Wall. Renew. Energy 2018, 119, 185-192.

24. Whittaker, C.; Shield, I. Factors affecting wood, energy grass and straw pellet durability-A review. Renew. Sust. Energ. Rev. 2017, 71, 1-11. [CrossRef]

25. Yank, A.; Ngadi, M.; Kok, R. Physical properties of rice husk and bran briquettes under low pressure densification for rural applications. Biomass Bioenergy 2016, 84, 22-30. [CrossRef]

26. Chou, C.-H.; Lin, S.-H.; Peng, C.-C.; Lu, W.-C. The optimum conditions for preparing for solid fuel briquette of rice straw by a piston-mold process using the Taguchi method. Fuel Process. Technol. 2009, 90, 1041-1046. [CrossRef]

27. Caputo, A.C.; Palumbo, M.; Pelagagge, P.M.; Scacchia, F. Economics of biomass energy utilization in combustion and gasification plants: Effects of logistic variables. J. Biomass Energy 2005, 28, 35-51. [CrossRef]

28. Ivanova, T.; Kabutey, A.; Herak, D.; Demirel, C. Estimation of energy requirement of Jatropha curcas L. seedcake briquettes under compression loading. Energies 2018, 11, 1980. [CrossRef]

29. Molari, L.; Maraldi, M.; Molari, G. Non-linear rheological model of straw bales behaviour under compressive loads. Mech. Res. Commun. 2017, 81, 32-37. [CrossRef]

30. Divišová, M.; Herák, D.; Kabutey, A.; Sigalingging, R.; Svatoňová, T. Deformation curve characteristics of rapeseeds and sunflower seeds under compression loading. Sci. Agric. Bohem. 2014, 45, 180-186. [CrossRef]

31. Lysiak, G. Fracture toughness of pea: Weibull analysis. Food Eng. 2007, 83, 436-443. [CrossRef]

32. Mani, S.; Tabil, L.G.; Sokhansanj, S. Effects of compressive force, particle size and moisture content on mechanical properties of biomass pellets from grasses. Biomass Bioenergy 2006, 30, 648-654. [CrossRef]

33. Gupta, R.K.; Das, S.K. Fracture resistance of sunflower seed and kernel to compressive loading. J. Food Eng. 2000, 46, 1-8. [CrossRef]

34. ASAE. Method of Determining and Expressing Fineness of Feed Materials by Sieving; Method S319; American Society of Agricultural and Biological Engineers (ASABE): St. Joseph, MI, USA, 2003.

35. Blahovec, J. Agromatereials Study Guide; Czech University of Life Sciences Prague: Prague, Czech Republic, 2008.

36. BS EN ISO 18134-3. Solid Biofuels_Determination in Moisture Content_Oven Dry Method_Part 3: Moisture in General Analysis Sample; BSI Standards Publication: Bonn, Germany, 2015; pp. 1-14.

37. ISI. Indian Standard Methods for Analysis of Oilseeds. In Indian Standard Institute; IS:3579; ISI: New Delhi, India, 1966.

38. StatSoft Inc. STATISTICA for Windows; StatSoft Inc.: Tulsa, OK, USA, 2013.

39. MathSoft Inc. Parametric Technology Corporation; MathSoft Inc.: Needham, MA, USA, 2014.

40. Herak, D.; Kabutey, A.; Divisova, M.; Simanjuntak, S. Mathematical model of mechanical behaviour of Jatropha curcas L. seeds under compression loading. Biosyst. Eng. 2013, 114, 279-288. [CrossRef]

41. Kabutey, A.; Herak, D.; Ambarita, H.; Sigalingging, R. Modeling of linear and non-linear compression processes of sunflower bulk oilseeds. Energies 2019, 12, 2999. [CrossRef]

42. Sigalingging, R.; Herak, D.; Kabutey, A.; Dajbych, O.; Hrabe, P.; Mizera, C. Application of a tangent curve mathematical model for analysis of the mechanical behaviour of sunflower bulk seeds. Int. Agrophys. 2015, 29, 517-524. [CrossRef]

43. Marquardt, D.W. An algorithm for the least-squares estimation of nonlinear parameters, SIAM. J. Appl. Math. 1963, 11, 431-441.

44. Kaewwinud, N.; Khokhajaikiat, P.; Boonma, A. Effect of biomass characteristics on durability of cassava stalk residues pellets. Res. Agric. Eng. 2018, 64, 15-19.

45. Tumuluru, J.S. Effect of process variables on the density and durability of the pellets made from high moisture corn stover. Biosysts. Eng. 2014, 119, 44-57. [CrossRef]

(C) 2020 by the authors. Licensee MDPI, Basel, Switzerland. This article is an open access article distributed under the terms and conditions of the Creative Commons Attribution (CC BY) license (http://creativecommons.org/licenses/by/4.0/). 